J. Dairy Sci. 92:777-781

doi:10.3168/jds.2008-1658

(c) American Dairy Science Association, 2009.

\title{
A randomized herd-level field study of dietary interactions with monensin on milk fat percentage in dairy cows
}

\author{
J. Dubuc, ${ }^{* 1,2}$ D. DuTremblay, ${ }^{*}$ M. Brodeur, ${ }^{*}$ T. Duffield,† R. Bagg, $\ddagger$ J. Baril, $\neq$ and L. DesCôteaux ${ }^{\star}$ \\ ${ }^{*}$ Faculté de Médecine Vétérinaire, Université de Montréal, C.P. 5000, Saint-Hyacinthe, Québec, J2S 7C6, Canada \\ †Department of Population Medicine, Ontario Veterinary College, University of Guelph, Guelph, Ontario, N1G 2W1, Canada \\ łElanco Animal Health, 150 Research Lane, Suite 120, Guelph, Ontario, N1G 4T2, Canada
}

\section{ABSTRACT}

This field trial evaluated the effects of dietary supplementation with $16 \mathrm{mg} / \mathrm{kg}$ (based on total dry matter intake) of monensin sodium on bulk tank milk fat percentage (MFP) of commercial dairy herds. Interactions between monensin and nutritional factors on MFP were studied. The trial was conducted in 47 Holstein dairy herds in Québec, Canada, between November 2005 and May 2006. The herd was the unit of interest. Enrolled herds were followed for a 7-mo period. Monensin treatment was randomly allocated in a crossover design where monensin was supplemented to the lactating dairy cow diet for a consecutive 12 -wk period. Twentyfour herds were allocated to monensin treatment for the first period of trial, and 23 herds were allocated for the second period. Diet composition and ration physically effective particle level were collected every 8 wk. Milk fat percentage data were retrieved from weekly bulk tank measures. Data were analyzed in linear mixed models using repeated measures within herd where MFP was considered the outcome variable. In addition to the main effect of monensin treatment, the following covariates were forced a priori into all statistical models: treatment period, weekly herd mean parity, and weekly herd mean days in milk. The majority of herds were fed a total mixed ration $(\mathrm{n}=29)$ and were housed in tie-stalls $(\mathrm{n}=42)$. Monensin significantly decreased bulk tank MFP by 0.12 percentage points. The reduction of MFP associated with monensin was larger for herds having a diet high $(>39.7 \%)$ in nonfiber carbohydrates, having a low level of physically effective particles in ration $(>45.0 \% ; \geq 8 \mathrm{~mm})$, and not feeding dry hay as first meal in the morning. Significant interactions between monensin and nutritional factors on

\footnotetext{
Received August 27, 2008.

Accepted October 20, 2008.

${ }^{1}$ Current address: Department of Population Medicine, Ontario Veterinary College, University of Guelph, Guelph, Ontario, N1G 2W1, Canada.

${ }^{2}$ Corresponding author: jdubuc@uoguelph.ca
}

bulk tank MFP were related to nonfiber carbohydrate and fiber concentrations in the diet.

Key words: monensin, dairy cow, milk fat, milk composition

\section{INTRODUCTION}

Monensin is a biological product produced by Streptomyces cinnamonensis (Richardson et al., 1976). It is classified as a monovalent carboxylic polyether ionophore (Bergen and Bates, 1984). Monensin alters the flux of ions across the membranes of gram-positive bacteria. This alters the bacterial population in the rumen and favors bacteria that synthesize propionic acid. Propionic acid is a precursor of glucose in ruminants. As a consequence, monensin has numerous potential positive benefits when fed to dairy cows, such as improved energy metabolism and decreased incidence of subclinical ketosis and abomasal displacement (Duffield and Bagg, 2000; Duffield et al., 2008a).

Monensin decreased milk fat percentage (MFP) in numerous studies, but there were wide variations between monensin effects reported. These variations can be explained by its method of delivery and by the dose of monensin administered to treated cows (Phipps et al., 2000; Mackintosh et al., 2002; Duffield et al., 2003). The reduction of MFP by monensin supplementation may be explained by an incomplete biohydrogenation process of long-chain fatty acids in the rumen that interferes with de novo fat synthesis in the mammary gland (Baumgard et al., 2000; Bauman and Griinari, 2003). Nutritional factors such as diet composition and feeding management were proposed to influence the effect of monensin supplementation on MFP (Duffield and Bagg, 2000). Nonetheless, there are few studies investigating the interactions between monensin supplementation and nutritional factors on MFP (Duffield et al., 2003; Alzahal et al., 2008).

Most studies that evaluated the effect of monensin on MFP used individual cows as the unit of interest (Ipharraguerre and Clark, 2003). Most studies involving feed-delivered monensin were conducted on research 
sites rather than commercial dairy farms because randomization of cows within a herd is extremely difficult in a field trial situation. Still, such a field experiment would provide useful data on dietary interactions with monensin because a larger number of herds would provide greater dietary variation.

Therefore, the main objective was to identify interactions between herd dietary factors and the use of monensin sodium at a dose of $16 \mathrm{mg} / \mathrm{kg}$ on bulk tank MFP. The second objective was to determine the herd-level effect of monensin on bulk tank MFP.

\section{MATERIALS AND METHODS}

Between November 2005 and May 2006, Holstein dairy herds $(\mathrm{n}=47)$ were enrolled in Québec, Canada, for participation in this field study. Herds used were required to use monthly DHI service for individual cow milk recording and were visited at least monthly by a veterinarian using the computerized data management system DSA (version 8.05, DS@HR, Saint-Hyacinthe, Québec, Canada) for reproduction and health management. The herd was the unit of interest. Monensin treatment period was randomly allocated at the herd level in a crossover design. Monensin (Rumensin premix, Elanco Animal Health, Guelph, Ontario, Canada) was added to the lactating cow diet for a consecutive 12 -wk period for every herd. Twenty-four herds received the monensin supplementation from November through January (period 1), whereas the other 23 herds did not. Then from March through May (period 2), monensin supplementation was switched. No herd was supplemented during a 4-wk period (February) for elimination of potential residual effects of monensin (washout). Herds were not allowed to feed any kind of monensin (premix or controlled release capsule) to cows from 3 mo before the beginning of the trial. No additional monensin (premix or controlled release capsule) was allowed during the trial period other than what was randomly assigned for treatment. The dose of monensin premix assigned was $16 \mathrm{mg} / \mathrm{kg}$ on a DM basis of the total diet. Monensin was diluted into a premix of minerals, protein supplement, or concentrates at the feed mill before being delivered to the farms. The accuracy of the dose of monensin fed to each herd was confirmed within the first month of the supplementation period by using the monensin concentration and the daily intake of supplemented feed. This experiment was approved by the Animal Care Committee of the Université de Montréal (Québec, Canada).

\section{Data Collection}

Bulk tank MFP were measured once weekly as part of routine commercial milk collection testing. A ques- tionnaire on nutritional management was completed by each farm manager at the beginning of the trial. Farm visits were performed every 8 wk. During each farm visit, a technician collected samples of wet forages and TMR for evaluation of DM content (Koster Moisture Tester, Koster Crop Tester Inc., Brunswick, $\mathrm{OH}$ ) and as-fed particle size distribution using a 2-sieve Penn State particle size separator (Lammers et al., 1996). Forage samples were collected from farm storage source. Total mixed ration samples were collected in the feed bunk in 3 different areas within an hour after feeding and were mixed together manually for creating a representative sample. The as-fed distribution of particles collected on the top 2 sieves was used as a practical indicator of physically effective particle level (PEPL) in ration. The use of PEPL measurement was adapted from the physically effective fiber estimation, which uses DM values (Yang and Beauchemin, 2006). The PEPL values were considered more practical for on-farm measurement. The composition and nutrient content of the main lactating group ration were retrieved every $8 \mathrm{wk}$ from the ration balancing program of each farm's nutritionist. Data collected were from standard infrared feed analysis (forages; Valacta, SteAnne-de-Bellevue, Québec, Canada) and average book values (concentrates). The diet composition data collected included amounts of feed ingredients $(\mathrm{kg}), \mathrm{DM}$ content (\%), NDF (\%), CP (\%), NFC (\%), $\mathrm{NE}_{\mathrm{L}}$ (Mcal/ $\mathrm{kg}$ ), starch (\%), and total lipids (\%). Herd average DMI per cow per day was estimated every 8 wk based on herd consumption and nutritionist's software. Collection of actual daily DMI data for each farm was not achievable under the conditions of this multi-site field study. Herd mean DIM and parity were retrieved and validated weekly from data management software.

\section{Statistical Analyses}

Statistical analyses were conducted using SAS (SAS Institute, 2005). The MEANS and UNIVARIATE procedures were used for descriptive statistics. Bulk tank MFP was the outcome variable in linear mixed models using the MIXED procedure in SAS accounting for repeated measures within herd. Herd was treated as random effect. In addition to the main effect of monensin treatment, the following covariates were forced a priori into all statistical models: treatment period, weekly herd mean parity, and weekly herd mean DIM.

The building of statistical models was done using 3 hierarchical steps. 1) Quantification of the effect of monensin treatment on bulk tank MFP was first assessed using a basic mixed model containing all the a priori forced covariates. Significance of monensin effect was declared as $P \leq 0.05$. 2) Identification of the 
Table 1. Herd population description (mean \pm SD) from 47 herds participating in a field trial investigating the effects of monensin ${ }^{1}$ supplementation $(16 \mathrm{mg} / \mathrm{kg})$ on bulk tank milk fat percentage

\begin{tabular}{lcccc}
\hline Variables & Mean & SD & Minimum & Maximum \\
\hline Number of lactating cows & 62 & 26 & 30 & 225 \\
Herd DIM & 172 & 22 & 120 & 220 \\
Herd parity & 2.5 & 0.3 & 1.9 & 2.9 \\
Herd milk production (kg/d) & 30.1 & 5.4 & 25.2 & 38.1 \\
Herd bulk tank milk fat (\%) & 3.98 & 0.18 & 3.62 & 4.30 \\
\hline
\end{tabular}

${ }^{1}$ Monensin = Rumensin premix, Elanco Animal Health, Guelph, Ontario, Canada.

significant interactions between monensin and dietary covariate was then performed. For this purpose, each dietary covariate and its interaction with monensin were tested in multivariable models containing all a priori forced covariates and using bulk tank MFP as the outcome. Significant covariates or interactions were retained if partial $\mathrm{F}$-test value was $P \leq 0.15$. A multivariable mixed model was built by manual backward elimination using all previously significant covariates and interactions, retaining those with a partial F-test $P$ value $\leq 0.05$. 3) Continuous covariates displaying significant interactions with monensin treatment in the final model were classified using the median or quartile values to give cut-off points for practical application. Least squares means of these interactions were compared using Tukey-Kramer contrasts $(P \leq 0.05)$. Evaluation of the distribution of residuals from the final model was assessed for normality and homoscedasticity.

\section{RESULTS AND DISCUSSION}

Descriptions of the 47 herds and their diet composition at the start of the study are presented in Tables 1 and 2. Most herds $(\mathrm{n}=29)$ were fed a TMR, whereas 18 herds were component-fed. Most herds $(\mathrm{n}=42)$ were housed in tie-stalls, whereas 5 herds were housed in free-stall barns. Of the 47 herds, 46 were fed corn silage, 45 were fed haylage, 43 were fed sodium bicarbonate, 10 were fed rumen-protected fat, 7 were fed whole flaxseed, and 6 were fed raw soybeans during the trial. Thirty-three herds were fed hay as first meal in the morning ( $>0.5 \mathrm{~kg}$ of $\mathrm{DM} / \mathrm{cow})$. The herd population enrolled was comparable to the population of small size dairy herds in Canada in regards to their size, milk production, feeding management, and housing facilities.

\section{Monensin Effect}

Monensin supplementation at a dose of $16 \mathrm{mg} / \mathrm{kg}$ decreased bulk tank MFP by 0.12 percentage points $(P<$ 0.01 ; Table 3). The size of monensin effect is consistent with previous studies that reported a decrease between 0.1 and 0.2 percentage points when fed at the same dose to dairy cows (Mackintosh et al., 2002; Duffield et al., 2003, 2008b). This effect of monensin on MFP is likely associated with incomplete biohydrogenation of longchain fatty acids in the rumen resulting in absorption of certain long-chain fatty acids that interfere with de novo fat synthesis in the mammary gland (Baumgard et al., 2000; Bauman and Griinari, 2003).

\section{Dietary Interactions}

Three significant interactions of dietary factors with monensin were found in the final model of this trial. Least squares means of bulk tank MFP accounting for these interaction terms are presented in Table 4.

Monensin treatment caused a greater bulk tank MFP decrease in herds fed a diet NFC concentration $>39.7 \%$ than in herds fed a lower diet NFC concentration. Duffield et al. (2003) reported an interaction between monensin and diet NFC concentration on MFP, such that monensin was only associated with decreased MFP when the diet NFC concentration was $<40.2 \%$. The results from Duffield et al. (2003) and the present study are in the opposite direction. Duffield et al. (2003) suggested that their finding about diet NFC

Table 2. Diet composition (mean $\pm \mathrm{SD}$ ) of 47 herds participating in a field trial investigating the effects of monensin ${ }^{1}$ supplementation (16 $\mathrm{mg} / \mathrm{kg}$ ) on bulk tank milk fat percentage

\begin{tabular}{lcl}
\hline Variables & Mean & SD \\
\hline Diet DM (\%) & 48.2 & 3.1 \\
CP (\% of DM) & 16.5 & 0.3 \\
NDF (\% of DM) & 31.5 & 0.8 \\
Starch (\% of DM) & 29.0 & 0.7 \\
NFC (\% of DM) & 39.7 & 0.6 \\
PEPL (\%) & 50.3 & 9.2 \\
Total lipids (\% of DM) & 3.6 & 0.6 \\
Ca (\% of DM) & 1.03 & 0.04 \\
P (\% of DM) & 0.46 & 0.03 \\
K (\% of DM) & 1.92 & 0.07 \\
Mg (\% of DM) & 0.35 & 0.02 \\
\hline
\end{tabular}

${ }^{1}$ Monensin $=$ Rumensin premix, Elanco Animal Health, Guelph, Ontario, Canada.

${ }^{2} \mathrm{PEPL}=$ physically effective particle level $=$ sum of as-fed proportions of particles retained on top 2 sieves of Penn State particle separator $(>8 \mathrm{~mm})$. 
Table 3. Basic mixed model using weekly repeated measures in 47 herds of the effect of monensin ${ }^{1}$ supplementation $(16 \mathrm{mg} / \mathrm{kg})$ on bulk tank milk fat percentage

\begin{tabular}{lcccc}
\hline Parameter & Class & Estimate & SE & $P$-value \\
\hline Intercept & & 3.85 & 0.10 & $<0.01$ \\
Monensin & No & 0.12 & 0.02 & $<0.01$ \\
& Yes & 0 & & \\
Period & 1 & 0.04 & 0.02 & 0.20 \\
& 2 & 0 & & \\
Herd parity $^{2}$ & & -0.01 & 0.03 & 0.74 \\
Herd DIM $^{2}$ & & 0.0003 & 0.0003 & 0.35 \\
\hline
\end{tabular}

${ }^{1}$ Monensin $=$ Rumensin premix, Elanco Animal Health, Guelph, Ontario, Canada.

${ }^{2}$ Weekly measure.

concentration might not be causal and hypothesized that there may have been a 3 -way interaction between monensin, NFC, and dietary unsaturated fat because there were much lower NFC values in their lower NFC group, and it was speculated that those diets contained a greater concentration of fat, although that trait was not measured. They reported that there was no formal randomization of treatment and that data originated from a cross-sectional observational study. Using such a study design, the results were more subject to potential confounding effects of unmeasured factors when compared with a randomized clinical trial. The present result is biologically plausible because diets high in NFC are expected to have a high level of concentrates, which would alter the rumen biohydrogenation process and exacerbate the milk fat depression effect of monensin (Bessa et al., 2000; Yang and Beauchemin, 2006).

Herds feeding monensin and a diet containing low PEPL $(\leq 45.0 \% ;>8 \mathrm{~mm})$ experienced an exacerbated MFP depression compared with herds feeding greater
PEPL (Table 4). Monensin treatment decreased MFP by interfering in the rumen biohydrogenation process of long-chain fatty acids (Bessa et al., 2000; Duffield et al., 2003). Diets containing a low PEPL likely had low physically effective fiber in diet, which could lead to subacute ruminal acidosis (Yang and Beauchemin, 2006). Diets low in PEPL can decrease stimulation of cud chewing and decrease the production of bicarbonate in saliva. This can decrease rumen $\mathrm{pH}$, decrease biohydrogenation of long-chain fatty acids, increase the production of trans fatty acids, and cause a reduction of MFP (Baumgard et al., 2000; Duffield et al., 2003).

Of all the feeding management practices surveyed, only 1 practice significantly interacted with monensin treatment on MFP: feeding dry hay $(\geq 0.5 \mathrm{~kg}$ of DM) as the first meal in the morning. This practice is relatively common in small Canadian dairy herds because it was performed by $70 \%$ of the herds enrolled. Herds not feeding dry hay in the morning experienced a greater reduction in MFP caused by monensin. Herds not feeding hay in the morning may be more likely to have lower level of PEPL in their diet and may be at greater risk of developing subacute ruminal acidosis and a reduction of MFP (Sutton, 1989; Duffield et al., 2003).

The nutritional factors (NFC, PEPL, and hay) presented previously have apparent independent effect according to the final model (Table 4). This situation could be explained by some variables being retrieved from the survey (hay) and some others being from feed analysis (NFC and PEPL). Furthermore, independence between NFC and PEPL value effects on MFP could be explained by the ration mixing process, which can highly influence the PEPL values and to a lesser degree the NFC values. The effects of many interactions

Table 4. Least squares means $( \pm \mathrm{SE})$ of bulk tank milk fat percentage accounting for monensin ${ }^{1}$ supplementation $(16 \mathrm{mg} / \mathrm{kg})$ effect stratified by diet NFC concentration, ration physically effective particle level (PEPL), and hay feeding as first meal in the morning from final mixed model using weekly repeated measures in 47 herds

\begin{tabular}{|c|c|c|c|c|c|}
\hline \multirow[b]{2}{*}{ Variables } & \multirow[b]{2}{*}{$\mathrm{n}$} & \multicolumn{2}{|c|}{ Milk fat percentage } & \multirow[b]{2}{*}{ Monensin effect } & \multirow[b]{2}{*}{$\mathrm{SE}$} \\
\hline & & No monensin & Monensin & & \\
\hline \multicolumn{6}{|c|}{ Diet NFC concentration $^{2}$} \\
\hline$\leq 39.7 \%$ & 24 & $3.97^{\mathrm{a}}$ & $3.85^{\mathrm{b}}$ & -0.12 & 0.03 \\
\hline$>39.7 \%$ & 23 & $4.03^{\mathrm{a}}$ & $3.85^{\mathrm{b}}$ & -0.18 & 0.03 \\
\hline \multicolumn{6}{|c|}{ Diet $\mathrm{PEPL}^{3}$} \\
\hline$\leq 45.0 \%$ & 11 & $4.04^{\mathrm{a}}$ & $3.82^{\mathrm{b}}$ & -0.22 & 0.03 \\
\hline$>45.0 \%$ & 36 & $3.99^{\mathrm{a}}$ & $3.86^{\mathrm{b}}$ & -0.13 & 0.03 \\
\hline \multicolumn{6}{|l|}{ Hay $^{4}$} \\
\hline No & 14 & $4.02^{\mathrm{a}}$ & $3.82^{\mathrm{b}}$ & -0.20 & 0.05 \\
\hline Yes & 33 & $3.97^{\mathrm{a}}$ & $3.88^{\mathrm{b}}$ & -0.09 & 0.03 \\
\hline
\end{tabular}

${ }^{a, b}$ Values within a row or within a column of same variable with different superscripts differ $(P<0.05)$.

${ }^{1}$ Monensin = Rumensin premix, Elanco Animal Health, Guelph, Ontario, Canada.

${ }^{2}$ Cut point is median NFC value during the study.

${ }^{3} \mathrm{PEPL}$ value represents sum of as-fed proportions of particles retained on the top 2 sieves of Penn State particle separator $(>8 \mathrm{~mm})$. Cut point is the 25 th percentile of PEPL distribution during the study.

${ }^{4}$ Hay $=$ herds feeding or not dry hay as first meal in the morning $(>0.5 \mathrm{~kg}$ of DM). 
between diet variables and monensin treatment have been investigated. Nevertheless, it was not possible to evaluate some nutritional measures having a potential effect on MFP such as the types of dietary lipids, polyunsaturated fatty acid concentrations, and fatty acid profile of dietary lipids.

\section{Herd-Level Field Study Design}

There are numerous experimental cow-level studies performed under controlled conditions for evaluating various effects of feed additives such as monensin, yeast, and enzyme (Yang et al., 1999; Dann et al., 2000; Ipharraguerre and Clark, 2003). Yet, studies evaluating the effects of feed additives under field conditions are necessary to describe responses under end-use conditions. Few such controlled field trials have been conducted because of the great challenge to randomize dietary treatments at the cow level on commercial dairy farms unless using tie-stall facilities (Swartz et al., 1994). For treatments that are applied at the group or whole-herd level, herd-level studies have advantages such as quantifying the effect of a treatment under field conditions, exploring farm management practices, exploring a variety of dietary contexts, and their interactions with treatment, considering the variation of effect between herds, and allowing inference to a larger population of herds. On the other hand, field studies have some weaknesses, such as less precision of measurement of cow-level measures (e.g., milk production). Experimental controlled studies using cow-level treatment allocation and randomized herd-level field trials are complementary means to assess the effects of feed additives.

\section{CONCLUSIONS}

Herd-level feeding of monensin to Holstein dairy cows at a dose of $16 \mathrm{mg} / \mathrm{kg}$ for $12 \mathrm{wk}$ decreased bulk tank milk fat on average by 0.12 percentage points. Nutritional factors including diet NFC concentration and ration PEPL influenced the effect of monensin on MFP. The results may help to predict the bulk tank milk fat response to monensin supplementation.

\section{ACKNOWLEDGMENTS}

We thank the participating farmers, veterinarians, and nutritionists for making this trial possible. We express our gratitude to François Dubois (Université de Montréal, Saint-Hyacinthe, Québec, Canada) for assistance in technical procedures on the feedstuffs. Gratitude is extended to Stephen LeBlanc (University of Guelph, Guelph, Ontario, Canada) for revision of the manuscript and extremely useful comments to improve it. This study was funded by Elanco Animal Health (Guelph, Ontario, Canada) and the Faculté de Médecine Vétérinaire of Université de Montréal (Saint-Hyacinthe, Québec, Canada). Jocelyn Dubuc was financially supported by Fonds du Centenaire of the Université de Montréal (Québec, Canada).

\section{REFERENCES}

Alzahal, O., N. E. Odongo, T. Mutsvangwa, M. M. Or-Rashid, T. F. Duffield, R. Bagg, P. Dick, G. Vessie, and B. W. McBride. 2008. Effect of monensin and dietary soybean oil on milk fat percentage and milk fatty acid profile in lactating dairy cows. J. Dairy Sci. 91:1166-1174.

Bauman, D. E., and J. M. Griinari. 2003. Nutritional regulation of milk fat synthesis. Annu. Rev. Nutr. 23:203-227.

Baumgard, L. H., B. A. Corl, D. A. Dwyer, A. Saeb, and D. E. Bauman. 2000. Identification of the conjugated linoleic acid isomer that inhibits milk fat synthesis. Am. J. Phys. 278:R179-R184.

Bergen, W. G., and D. B. Bates. 1984. Ionophores: Their effect on production efficiency and mode of action. J. Anim. Sci. 58:14651483.

Bessa, R. J. B., J. Santos-Silva, J. M. R. Ribeiro, and A. V. Portugal. 2000. Reticulo-rumen biohydrogenation and the enrichment of ruminant edible products with linoleic acid conjugated isomers. Livest. Prod. Sci. 63:201-211.

Dann, H. M., J. K. Drackley, G. C. McCoy, M. F. Hutjens, and J. E. Garett. 2000. Effects of yeast culture (Saccharomyces cerevisiae) on prepartum intake and postpartum intake and milk production of Jersey cows. J. Dairy Sci. 83:123-127.

Duffield, T. F., and R. Bagg. 2000. Use of ionophores in lactating dairy cattle: A review. Can. Vet. J. 41:388-394.

Duffield, T., R. Bagg, D. Kelton, P. Dick, and J. Wilson. 2003. A field study of dietary interactions with monensin on milk fat percentage in lactating dairy cattle. J. Dairy Sci. 86:4161-4166.

Duffield, T. F., A. R. Rabiee, and I. J. Lean. 2008a. A meta-analysis of the impact of monensin in lactating dairy cattle. Part 2. Metabolic effects. J. Dairy Sci. 91:1334-1346.

Duffield, T. F., A. R. Rabiee, and I. J. Lean. 2008b. A meta-analysis of the impact of monensin in lactating dairy cattle. Part 1. Production effects. J. Dairy Sci. 91:1347-1360.

Ipharraguerre, I. R., and J. H. Clark. 2003. Usefulness of ionophores for lactating dairy cows: A review. Anim. Feed Sci. Technol. 106:39-57.

Lammers, B. P., D. R. Buckmaster, and A. J. Heinrich. 1996. A simple method for the analysis of particle sizes of forages and total mixed rations. J. Dairy Sci. 79:922-928.

Mackintosh, E. D., R. H. Phipps, J. D. Sutton, D. J. Humphries, and J. I. Wilkinson. 2002. Effect of monensin on rumen fermentation and digestion and milk production in lactating dairy cows. J. Anim. Feed Sci. 11:399-410.

Phipps, R. H., J. I. Wilkinson, L. J. Jonker, M. Tarrant, A. K. Jones, and A. Hodge. 2000. Effect of monensin on milk production of Holstein-Friesian dairy cows. J. Dairy Sci. 83:2789-2794.

Richardson, L. F., A. P. Raun, E. L. Potter, C. O. Cooley, and R. P. Rathmacher. 1976. Effect of monensin on rumen fermentation in vitro and in vivo. J. Anim. Sci. 43:657-664.

SAS Institute. 2005. SAS User's Guide: Statistics. Version 9.1 ed. SAS Inst. Inc., Cary, NC.

Sutton, J. D. 1989. Altering milk composition by feeding. J. Dairy Sci. 72:2801-2814.

Swartz, D. L., L. D. Muller, G. W. Rogers, and G. A. Varga. 1994. Effect of yeast cultures on performance of lactating dairy cows: A field study. J. Dairy Sci. 77:3073-3080.

Yang, W. Z., and K. A. Beauchemin. 2006. Physically effective fiber: Method of determination and effects on chewing, ruminal acidosis, and digestion by dairy cows. J. Dairy Sci. 89:2618-2633.

Yang, W. Z., K. A. Beauchemin, and L. M. Rode. 1999. Effects of an enzyme feed additive on extent of digestion and milk production of lactating dairy cows. J. Dairy Sci. 82:391-403. 